\title{
Drawing Up an Institutional Architecture
}

Much of the research on early childhood development focuses on evaluating the impact of interventions and developing best practices. However, interventions are not implemented by fiat; they take place in a cultural, socioeconomic, and institutional context that affects both whether best practices are implemented and how effective they will be. Ultimately, the institutional arrangements a country puts in place to implement public policy have important implications for the quality, equity, and sustainability of early childhood services.

The institutional architecture behind the implementation of public policy in early childhood development is unique in the public sector and critical to its success for several reasons. First, services should be delivered in a synergistic manner over a relatively short period of the life cycle. Second, responsibility for interventions is spread across a variety of departments including education, health, and social protection; in many countries, these services are further spread across federal, provincial, and local levels of government. Coordination across levels and among departments is a major challenge. Finally, in addition to public institutions, private and not-for-profit providers play important roles in delivering services and require further coordination and regulation. All these challenges magnify both the importance of the institutional architecture and the difficulties of policy implementation.

This chapter analyzes the institutional arrangements that affect the implementation of public policy in early childhood. It is based on a thorough study of a number of country cases in the region, which offer examples of the spectrum of institutional approaches to public policy toward young children in Latin America and the 
Caribbean: Brazil, Chile, Colombia, Guatemala, and Trinidad and Tobago. ${ }^{1}$ These country cases reflect the main challenges that the region faces in building a strong institutional architecture to support program delivery.

\section{The Lay of the Land}

The way in which a country regards its obligation to young children is embedded in its sociocultural history, which defines not only what services should be delivered, but also how and to whom they are delivered. How policymakers across much of Latin America and the Caribbean think about early childhood development has undergone three recent shifts.

First, policymakers are recognizing the importance of focusing on children during their early years. This heightened awareness has translated into service expansion either by increasing services to more children within the same age group, extending services to younger children, and/or diversifying the kinds of services delivered. While the institutional mechanisms chosen for such expansion vary from country to country, policymakers agree that services still need to be expanded and improved.

Second, there is a growing consensus that early childhood services are a universal human right and should be guaranteed by government intervention either directly through public provision or indirectly by financing and regulating private providers. Some countries, like Brazil, prioritize direct public provision as the policy option to ensure this right. Other countries, like Trinidad and Tobago, have also voiced a commitment to young children, but to date the public sector has provided limited services.

Third, a conceptual shift in the delivery of services in the early years is under way. Countries are moving away from a model of fragmented service providers (such as health, education, or social protection) toward an integrated approach that considers the comprehensive development of each child. The extent of this change, however, varies considerably across countries. In many countries in the region, such as Brazil, Chile, Colombia, and Trinidad and Tobago, early childhood development is increasingly viewed as a 
multidimensional phenomenon. However, in other countries, such as Guatemala, the focus on young children is still primarily directed toward health and nutrition.

Despite these increased commitments and important conceptual shifts, a large gap persists between discourse and implementation. The development of a strong institutional architecture is required to ensure quality, equitable, and comprehensive policies for young children in the region.

\section{Four Pillars for a Strong System}

This chapter focuses on four critical pillars that support the implementation of public policy in early childhood: governance, finance, quality assurance, and human capacity (Kagan and others forthcoming). Box 7.1 describes this framework and other approaches to study this issue. The strength of these pillars varies across countries and reflects the challenges the region faces in building a strong foundation for their institutional architecture.

\section{Box 7.1 Approaches for Analyzing the Institutional Architecture of Early Childhood Service Provision}

Increasing awareness of the importance of early childhood development has led to a corresponding increase in scholarly interest in the institutional architecture of systems to oversee these programs. Scholars have suggested a number of different approaches to understanding their architecture (Sugarman 1991; Bruner 1996; Kagan and Cohen 1996; Kagan and Kauerz 2012). The broadest framework, Bruner (2004), suggests that a system for young children must address health and nutrition, family support systems, early care and education services, and services for children with special needs or early intervention systems. Kagan and Cohen (1996) defines a system as having programs or direct services and an infrastructure to support these services; the infrastructure consists of governance; finance; quality, standards, and transitions; assessment, data, and accountability; human capacity development; family and community engagement; and linkages with external influencers. Vargas-Barón (2013) defines eight elements of 
an early childhood development system, including equity and rights; multisectorality, integration, and coordination; governance; legislation, standards, regulations, and agreements; quality improvement; accountability; investment; and policy advocacy and social communications. Coffman and Parker (2010) suggest that systems building must take the following elements into consideration: context, components (services and programs), and connections; infrastructure (governance and administrative supports); and scale. In their framework paper-one in the series of Systems Approach for Better Education Results (SABER) Neuman and Devercelli (2013) suggest that systems implementation includes the establishment of a supportive environment, the wide-scale implementation of services, and the monitoring and assurance of quality. Finally, building on systems theory, Britto and others (2014) and Yoshikawa and others (2014) have examined elements of systems in four low- and middle-income countries with a focus on planning, implementation, coordination, and financing mechanisms.

This chapter adopts the framework developed by Kagan and Cohen (1996), which posits that an early childhood development system is composed of both individual programs and an infrastructure that supports those programs. Based on the methodology described in Kagan and others (forthcoming), this chapter focuses on four elements of the infrastructure that are critical to the delivery of quality, equitable, and sustainable services: governance, finance, quality assurance, and human capacity (the framework also includes family and community engagement and linkages with external influencers, which this analysis forgoes). These elements of the early childhood development infrastructure act as a booster or a limitation to the implementation of individual programs and services. Good governance, for example, ensures that services are coordinated across sectors so programs do not overlap or work at cross-purposes. Proper financing mechanisms ensure sufficient resources initially and secure funding for the life of the program. Quality assurance requires national measures and standards to supplement program-specific standards. The availability and pertinence of data in the country may limit evaluation options in individual programs. Finally, programs require well-trained human resources. While human resource development may be included as an individual program feature, the actual availability of a pool of welltrained potential personnel depends on elements that transcend the individual program, including the general mechanisms to attract qualified individuals to work in early childhood development, salary structures for the sector, and the quality of pre-service training of workers. 


\section{Governance: Who Does What, and How?}

Along with the move toward a more comprehensive understanding of early childhood development, some countries in the region have been developing integrated governance mechanisms among the various sectors and institutions responsible for programs and policies. The idea behind this shift is to organize services around the comprehensive development and needs of each child and his/her family, rather than that of service providers. Both horizontal coordination (among sectors such as health, nutrition, sanitation, education, labor, and social protection) and vertical coordination (across national, subnational, and local levels of government) are important for implementing integrated services.

One solution to assure horizontal and vertical coordination has been the development of boundary spanning entities (BSEs) - institutions with an explicit mandate to coordinate efforts among the myriad of relevant institutions. The push for the use of BSEs has been strongest in Chile and Colombia with Chile Crece Contigo (ChCC) and De Cero a Siempre (DCAS), respectively (see Box 7.2 for more on ChCC).

\section{Box 7.2 Chile Crece Contigo: Comprehensive Early Childhood Policies}

In 2006, President Michelle Bachelet appointed a Presidential Advisory Council for the Reform of Policies for Children, with the mandate to design a comprehensive child protection system. Following the council's recommendation, on October 2006, President Bachelet launched Chile Crece Contigo (ChCC), and in 2009, a law formalized its existence. ChCC established an intersectoral system of social protection in charge of the comprehensive development of young children (from gestation until age 4).

What makes ChCC innovative is that it articulates, organizes, and integrates the services provided by the health, education, welfare, and protection services based on the needs of young children and their families. A child's first contact with the system occurs in utero, during her mother's first prenatal control. Part of the success of the system relates to the very large coverage and utilization of the public health network 
throughout the country. It is in the clinic that each family is assessed not only on its health, but also on a number of areas of socioeconomic vulnerability. Through this evaluation, families can be referred to specific services provided in their municipalities by other sectors (anything from a poverty alleviation program to a childcare service, home visits, housing improvements, or screenings for developmental delays). The intersectoral structure of ChCC highlights the multidimensionality of child development and the importance of making multiple supports and interventions available simultaneously.

ChCC articulates services that are of universal coverage and others that are designed to reach the most vulnerable. An example of a universal service is education programs aimed at reaching all families in the country with information on child stimulation and development, delivered through mass media and the Internet. An example of a targeted service is access to poverty alleviation programs, a subsidized childcare slot, or specialized assistance for children with disabilities.

Chile has opted to manage horizontal intersectoral coordination by superimposing institutional arrangements over existing institutions in charge of managing service provision. Organizationally, ChCC resides in the Ministry of Social Development and coordinates service provision across government agencies. Management of service provision remains the responsibility of line ministries, such as health and education. ChCC is implemented through contracting mechanisms between the Ministry of Social Development and the line ministries that manage and regulate service provision. Contracts stipulate which services are to be provided and how they will be monitored.

To vertically coordinate national, regional, and municipal service providers, ChCC has developed specific structures at each level of government. At the national level, a central unit coordinates actions across the national-level ministries. At the regional level, coordination is the responsibility of the regional representative of the Ministry of Social Development, who acts as the regional coordinator of ChCC and convenes the regional representatives of the line ministries. At the municipal level, a local level coordinator and municipal networks of local providers manage intersectoral coordination.

Recognizing that in decentralized countries the success of the BSE depends on the actions taken at the local level, ChCC has 
developed mechanisms to strengthen implementation capacity at this level. ChCC earmarks specific funds for municipalities to manage local coordination, uses a data system to track policy implementation at the local level, and provides training to municipal officials in intersectoral management and the use of this data system.

The institutional choices made by ChCC are just one way in which a more consolidated approach to governance can be organized. Others exist. Colombia's DCAS has some institutional features similar to ChCC, but others that respond specifically to the Colombian context. In the case of DCAS, the central coordinating agency is not part of any particular line ministry, but rather of the president's office, signaling a strong political mandate for coordination. On the other hand, DCAS does not have a direct operational structure. Consequently, it has no staff at the regional and local levels, and coordination relies on the varying degrees of effort and commitment of line ministry and local government representatives-resulting in important implementation challenges.

While BSEs are an attractive tool for coordinating policy and services, conflict is intrinsic to them. BSEs attempt to realign deeply rooted practices and ideas in line ministries. Employees and managers in line ministries are not yet held accountable for coordinating with other sectors; as a result, they have little incentive to cooperate with coordination efforts. Instead, line ministry employees often see cross-sectoral coordination as an add-on to already heavy workloads. Furthermore, BSE staff requires specific knowledge and skills to implement coordination goals successfully. In the case of Chile, professional development efforts have been undertaken to change practices and ideas in line with the new approach, but there is still room for improvement.

Chile and Colombia share many of the same challenges. For coordination mechanisms to be successful, they must change existing practices, assure adequate human and financial resources, and develop new incentive structures that promote coordination and better human resources. A comprehensive move to an integrated system requires extensive time and effort. These efforts must also include coordination and regulation of nongovernmental actors (see Box 7.3 on the role of nongovernmental actors). 


\section{Box 7.3 Partnering for Children}

Government agencies and officials are not alone in pushing for an increased focus on young children's issues in the policy agenda; nongovernmental actors have played a major role in bringing children and their families to the forefront. These so-called external influencers include individuals from civil society, grassroots organizations, academics, the business sector, and international organizations, all of whom have strong voices in matters relating to the protection and the development of young children. External influencers not only promote and support policies for young children, but they can also work to create consensus regarding other aspects of the policy process in areas such as accountability, monitoring and evaluation, or standards.

The degree of influence of nongovernmental actors and the channels though which they exercise this influence vary from country to country. There are two main types of partnership arrangements between the public sector and external influencers. In the first type, external influencers partner with governmental initiatives for young children, as early childhood development is positioned on the social and governmental agenda. They not only promote and support policies for young children and their families, but can also work to create consensus regarding other aspects of the policy process in areas such as accountability, monitoring, evaluation, or standards. A second type of partnership occurs when external influencers provide support to directly implement social policies and programs and provide services.

When the appropriate coordination between governmental initiatives and the external influencer exist, these partnerships are beneficial. However, that is not always the case. The case of Guatemala deserves special mention: a myriad of private entities, nongovernmental organizations, and international organizations pour resources into the country to support efforts in education and health-but there is an important need to better channel and coordinate donor efforts so that the intended objectives are met. Beyond the challenges of donor coordination, Guatemala seems to require a deeper dialogue among all the key actors (government and external influencers) on the priorities and vision for early childhood development policies and programs. 
Despite the many challenges faced by Chile, Colombia, and others, recognizing the importance of coordination is a positive step, and as more countries move in this direction, the number of inventive solutions to the problems faced by all should increase.

\section{Finance: Money-and Its Distribution-Matters}

Public funding for services for young children in the region has increased (see Chapter 6). In Brazil, for example, spending (including health, education, and social protection) on early childhood grew by 7 percent annually between 2004 and 2012 (Tavares de Araujo and Cavalcanti de Almeida 2014), well above the corresponding 4.25 percent rate of GDP growth. Despite the expansion in budget allocations, spending on the early years is still insufficient to fund not only an adequate supply of high-quality services, but also to sustain the institutional elements that assure quality, equity, and sustainability.

Some countries rely on sporadic sources of funding including private sources, redirected budget surpluses, and royalties related to natural resource exports, which make the provision of services unpredictable. This, of course, hampers the development of longterm initiatives as funding is tied to government priorities within and across political cycles. Even in countries that have developed more sustainable funding mechanisms, early childhood is still a second-tier area. For example, in Brazil, while the constitution sets expenditure floors for both health and education, it makes no specific provision for expenditures on early childhood.

Even when funding is sufficient and sustained, it needs to be strategically allocated to support the timely implementation of quality services. Generally, funding is based on implementing specific programs within sectoral lines, and not necessarily tied to indicators of service quality. This tends to introduce intersectoral competition for funding, redundancies in programs, and a suboptimal resource allocation.

The equitable allocation of funding across local governments is a source of concern, particularly in countries where funding (and service provision) is decentralized. In those cases, local funding 
for services comprises a national/federal share and a local share. Wealthier local governments can supplement federal funding with their own resources, reinforcing regional inequality. However, some countries are attempting to compensate for these inequities in funding by developing redistribution mechanisms. In Brazil, for example, FUNDEB (Fundo de Manutenção e Desenvolvimento da Educação Básica e de Valorização dos Profissionais da Educação) provides additional resources to localities that are unable to guarantee a minimum level of expenditure per child per year. The redistribution formula weighs factors such as the population attending daycare, preschools, and elementary schools, as well as the percentage of urban and rural students (see Box 7.4 for more on the challenges of decentralization in Colombia).

\section{Box 7.4 The Challenges of Decentralization in Colombia}

In Colombia, young children's differential access to services is a critical issue that produces unintentional inequities that may persist throughout their lives. There are multiple reasons for service inequities, with family income and location being foremost among them.

Geographic location is a considerable source of inequalities. Young children from wealthier, more urban areas have greater access to services than poorer, more rural children. Service inequities also exist by age. For example, 4-year-old children attending an early education centerbased modality receive 70 percent of their nutritional requirements, but when these same children go to kindergarten at age 5, they are lucky to receive any nutritional support through the school nutrition program, as nutrition is not universally provided to all youngsters in the school system. Moreover, there are the differences in schedules between early education services, which are full time, and formal schooling, which are part-time. These might be causing problems in the transitions to formal schooling by making parents delay entry into kindergarten.

An unintentional element that can potentially exacerbate inequality relates to the decentralized administrative structure of the country. Children born or living in richer regions of the country who use public services could be receiving better quality services than those living in less well-off areas. For example, Bogota, Medellin, Barranquilla, and Cali consider early childhood services so essential that they 
supplement central government funds with local resources to provide services for youngsters. In addition, these cities exert some control over quality by, for example, in Bogotá, mandating private operators to be registered and establishing quality criteria that facilities have to meet in order to operate.

Economic and geographic status is not the only source of inequity; structural inhibitors exist as well. In Colombia, inequities seem to be unintentionally reinforced by a commitment to the decentralization of decision-making and service delivery, without a strong compensatory mechanism in place. In adhering to the need for customization of services, the management tool created to support the comprehensive provision of services (Ruta Integral de Atenciones, or RIA) is expected to be customized to respond to varying contexts. The construction of customized RIAs in each municipality has proven to be a highly complex task, in part, because the levels of commitment to early childhood development and the technical capacity of local authorities vary heavily across municipalities and departments.

Such heterogeneous implementation mirrors and perhaps reproduces the social and economic disparities within diverse subnational governments. Children's limited and uneven access to services is a practical reality that compromises youngsters' optimal development. It also contradicts the good intentions of promoting the rights of all children and supporting their full development. The reality is that children's experiences in early childhood services are heavily conditioned on their family income and their area of residence, among other factors.

\section{Quality Assurance and Accountability: Setting Up a Virtuous Circle}

Quality assurance can be thought of as a (virtuous) circular process. It begins with a statement of the required characteristics of services and the outcomes they are expected to produce. Then, it moves to the mechanisms in place to measure whether such outcomes are achieved, and if not, why. Finally, the circle closes with mechanisms that allow for changes to be made based on the assessment of these outcomes. While there has been progress in introducing quality assurance processes, in most cases they are still limited in their design and implementation. 


\section{Outcome and Service Standards}

Quality assurance processes begin by determining the required characteristics and expected outcomes of services. The growing consensus is that this can be achieved by developing and implementing child and services standards. Child standards specify the age-specific and measurable outcomes that services are trying to achieve. In early childhood development, these are often referred to as early learning and development standards. Service standards, on the other hand, relate to the nature of the services children should receive. They specify parameters of health, safety, and space; they may also refer to the dosage and duration of the services needed to be part of an effective protocol. ${ }^{2}$

Countries in Latin America and the Caribbean tend to assign limited attention to child outcome standards. Particularly in relation to learning, there is a hesitation to specify what young children should know and be able to do. This reflects, in part, the fear that specifying outcomes might lead to unfair and premature labeling or tracking of young children. Despite the scarcity of precise standards for children's outcomes, some child development curricula specify very general outcomes for children. In several cases, however, the curricula are considered guidelines; their usage, while recommended, is not required.

In contrast to the paucity of child outcome standards, service standards are much more abundant. It is common to have program standards for the major educational stages, as well as standards for most health and social protection programs. The mere existence of standards, however, is not an effective barometer of success; the content and quality of the standards must be examined. Often, they focus on what can be easily counted, rather than on process variables that may have a greater impact on outcomes. In the education sector, this tendency results in an abundance of standards that address structural variables or variables that are easy to regulate, such as group size, child-to-adult ratios, and teacher pre-service training requirements. Attention to process variables, such as teacher-child interactions, is absent, even though they are most directly linked to child outcomes. In the health sector, service standards focus mainly on the number of services delivered or on administrative and/or contractual data, rather than on service quality. 
It is common for several sets of standards to coexist for similar types of services. This occurs for a number of reasons. First, standards tend to be developed at the program level, rather than at the system level. A typical example involves the services provided by JUNJI (Junta Nacional de Jardines Infantiles) and INTEGRA (Fundación Nacional para el Desarrollo Integral del Menor) in Chile. Both are public providers of daycare services for the same age group. However, each institution has its own set of standards, which results in differences in service provision. Second, standards at the local and central levels of government, and across local governments, are rarely aligned. This can result in regional inequities in the quality of services provided. In Colombia, for example, standards can be altered to meet the needs of the local context. However, this can exacerbate regional inequality, depending on the quality of standards that are developed and implemented in each locality. Third, in many countries, standards do not consistently apply to both public and private sector providers, thus exacerbating differences in the services provided.

The appropriate service characteristics and pedagogical approaches, as well as the expected child outcomes, vary depending on the age of the child, and as young children transition from home to daycare and from daycare to schools. To ensure continuity of experience, outcome and service standards need to be aligned across services catering to different age groups. This can be achieved by having structured transitions. With the exception of Trinidad and Tobago, most countries have neglected transitions. Trinidad and Tobago has developed a curriculum guide that promotes smooth transitions for young children across service modalities. For example, it stresses the importance of transferring records and addressing the continuity of children's pedagogical experiences. There is limited data available, however, to verify the implementation of transition efforts or their success.

\section{Data and Monitoring}

Data production and monitoring systems-a crucial component of quality assurance processes-allow public officials, researchers, evaluators, and others to measure whether the expected service characteristics and child outcomes are actually being achieved. While 
policymakers acknowledge the importance of data to inform policy decisions, the actual availability and use of data and monitoring systems for quality improvement are still limited.

Data and monitoring systems face challenges in four main areas: practical (a focus on inputs over outputs); conceptual (using data systems as repositories rather than as tools for quality enhancement); attitudinal (a hesitation to obtain developmental information at the child level); and technical (the lack of adequate instruments or human capacity).

Among practical challenges, data systems in most countries amass information on programmatic inputs (such as cases attended in clinics, children in school, and beneficiaries of a specific program) and tend to use such information for accountability purposes against output standards (such as number of children per classroom and amount spent on materials). Much less attention is devoted to collecting indicators of results, outcomes, or impacts (such as developmental indicators at the child level). This limits the use of available data for accountability that goes beyond outputs. For example, the health sector clearly needs to evolve beyond data sets focused exclusively on numbers of people served. Countries see the importance of transitioning toward nominal data systems, where the unit of analysis is the individual, so that individuals and the interventions they receive can be tracked throughout and/or within a given sector, or ultimately merged across sectors.

The lack of results and impact measurements also springs from a lack of consensus on the need for measuring quality, as well as on how best to measure it. Data systems act largely as repositories for information about service delivery, rather than as vehicles for quality enhancement and policy development.

Attitudinally, the assessment of young children is a source of much debate and angst in many countries of the region. From a public policy perspective, however, this information is a necessary condition to develop more effective programs and interventions that can best optimize children's development.

Finally, there are a number of technical challenges. First, an important issue is the appropriateness of the instruments and diagnostic tools to carry out assessments in early childhood. Municipal-level 
initiatives to collect child development data have been completed in Rio de Janeiro, and data on provider-level quality for center-based care services have been collected in Florianopolis, Brazil. Critics of many current assessments base their skepticism on differencesmostly cultural-that, they argue, make it difficult to generalize expectations regarding what young children should know or be able to do at a given age. Despite the difficulties involved, however, countries in the region urgently need to agree on a set of instruments for measuring early child development that can be collected on representative samples of individuals, as is done in the household surveys, and others that can be collected for the population at large.

Second, data are not always up-to-date or well aggregated. For example, whether due to fiscal limitations or governmental choices, or both, Guatemala relies on census data that are more than a decade old. That current data do not exist is troublesome as it is the only available information to determine the siting of programs and the allocation of resources. Data aggregation is also challenging. In Trinidad and Tobago, for example, fairly recent data are collected and even reported, but much of the data is aggregated for children from birth to 19 years of age. Given this aggregation frame, it is difficult to filter out relevant data to improve programs or for other key decisions that affect age-related services for younger children.

Third, shortcomings in institutional and human capacities contribute to all of the challenges involved in generating, managing, and using information systems. In some countries (and in less-developed regions within all countries), technological gaps and connectivity problems still impose constraints on the construction of modern data systems. Technical and institutional capacity varies greatly not only between countries, but also across different sectors and institutions within each country.

Conceiving quality from a systemic perspective requires thinking beyond programmatic data collection efforts toward more systemic collection and utilization of data. Data collection efforts do not necessarily need to be integrated into one central database; they can still be housed in separate sectors. What makes them systemic is that the different data sets are conceived as part of an integrated system, with the data being available to, and easily merged with, 
data from other ministries. This type of organization requires strong central planning.

In some countries, such as Chile, BSEs have consolidated data systems that foster data integration. Other countries, such as Brazil, have also moved toward data integration even in the absence of a formal BSE. An example is the Cadastro Unico in the Brazilian conditional cash transfer program, Bolsa Familia. Information on health, education, and social protection is collected for different purposes, but mainly to check on the degree to which the beneficiaries meet the requirements, and then to take action at the municipal and individual levels. In the case of the Cadastro Unico, the information is not only shared horizontally between ministries, but also vertically between the federal government and the municipalities, which receive budget resources based on meeting specific performance indicators.

\section{Closing the Accountability Circle}

The circle of accountability and quality assurance is closed when countries introduce mechanisms that allow for changes to be made when standards are not met. The development of these mechanisms is still weak in most countries. Accountability processes can promote change in policies and programs in at least three ways: by establishing regulatory mechanisms that enforce consequences for noncompliance with standards; by publicizing information so that social actors can participate in an informed manner in decisionmaking; and by promoting direct involvement of families at the center/service level.

Mechanisms that trigger consequences for noncompliance with standards are still at the very early stages. As mentioned, countries are trying to produce data on policies and programs, but these data still focus on outputs rather than on outcomes. Thus, mechanisms that introduce consequences tend to focus on noncompliance with program standards, rather than on the quality of service provision or the outcomes achieved by children. For example, in the case of Chile, the Ministry of Social Development has recently been tasked with evaluating social programs to determine whether funding for specific programs should be continued. In the case of early childhood 
programs, such decisions are limited by the availability of data on quality and child outcomes.

Accountability processes can also be informed by community members who formally and informally influence decisions regarding service provision. The councils at the municipal/community level in Brazil are an example. Councils function as a public accountability mechanism by monitoring the work of government. For community members to make informed decisions, data on early childhood development need to be publicly available. Only a few national and subnational governments, including in Brazil, make data publicly accessible. These commendable data-sharing efforts can make information available to citizens, expand public accountability processes, and enhance family and community engagement in planning services for children.

Finally, engaging families in their children's programs at the point of service provision may also act as an accountability mechanism; families can and informally do observe programs and can consequently affect change at that level. Family engagement also allows for more informed decision-making regarding priorities and local needs; furthermore, it can help build consensus about child development and needed services. In general, however, family members are most often seen as providers of resources or labor (including caregiving, food preparation, or improvements of physical infrastructure), rather than as a possible force for quality improvement.

\section{Human Capacity: The Weakest Link}

High-quality programs rely on highly qualified staff. In order for services to be staffed with high-quality personnel, the system needs to ensure that enough professionals have the right competencies to perform their functions and that incentive structures attract and maintain top professionals. ${ }^{3}$ Human capacity is one of the weakest elements of the institutional infrastructure in the region. This gap stems mainly from two factors: overreliance on the use of community members and families as the workforce for some services; and poorly designed personnel requirements and policies that do 
not effectively produce and maintain a high-quality professional workforce.

Some countries rely on the labor of families or community members to provide services (including caregiving, food preparation, or improvements in physical infrastructure). In Colombia, for example, a large share of daycare provision has historically relied on community mothers with little training, as discussed in Chapter 4. They receive a modest government transfer to provide childcare services to small groups of neighborhood children in their own homes. This strategy increases the number of staff available, while also increasing employment opportunities for low-income families. Nevertheless, this approach has many limitations. It relies completely on unqualified staff with little supervision and few mentoring and training opportunities. Moreover, the system does not provide incentives, such as remuneration or career advancement, to build and maintain quality human resources. In recent years, Colombia's government has taken an important step toward formalizing the employment conditions of community mothers. This initiative is likely to reduce turnover and attract more qualified individuals. In addition, efforts have been made to train community mothers in key competencies for their jobs through the country's main adult training services.

Where programs require professional credentials to work with young children, personnel policies are not well-designed to effectively produce a high-quality professional workforce. For instance, early childhood educators tend to be treated as a lower-tier of workers within the education profession. This occurs for a variety of reasons: low entry requirements, inadequate compensation schemes, and poor in-service professional development.

Entry requirements for the profession are lower than for other types of educators. In countries where early childhood is understood as a field of specialization, pre-service or initial teacher education programs for early childhood educators tend to attract less-qualified students compared to primary or secondary educator programs. Teaching in most pre-service training programs is considered to be of low quality and academic requirements for completion are less stringent than in teacher training programs for primary or secondary school educators. 
Early childhood educators often face inadequate and inequitable compensation schemes. They tend to have lower remuneration and less attractive career paths than primary and secondary school teachers. Of course, this makes the early childhood field less attractive to qualified individuals. To make matters worse, in decentralized countries such as Brazil and Colombia there are significant regional differences in salaries for public sector workers, where wealthier municipalities can offer more competitive salaries. This generates a shortage of qualified early childhood educators in less affluent areas, which is where the returns to their skills are likely to be highest.

Finally, opportunities for staff training tend not to be systematic. This happens both at the pre-service and the in-service level. There is little regulation of pre-service training providers, which results in varying quality levels among institutions. In-service training initiatives, in turn, tend to be scattered, with limited continuity and little alignment to the identified needs of staff. Some countries are trying to provide training more systematically, to ensure that all early childhood educators acquire a core set of competencies. In the case of pre-service education, Trinidad and Tobago is focusing on the consistency of training across providers, with aligned pre-service training programs for teachers of children aged 3-5 across a network of eight universities, described in detail in Box 7.5. In the case of inservice initiatives, the federal Ministry of Education in Brazil has developed the National Network for Continuing Teacher Education (Rede Nacional de Formação Continuada de Professores) to support the professional development of teachers. The ministry is currently developing curriculum guidelines for educators to be implemented through the network.

\section{Box 7.5 Teacher Training in the Tropics}

A necessary condition for expanding coverage of high-quality early childhood services is the availability of qualified human resources who can serve young children and their families in all types of services: nutritional, health, education, protection, and other. However, the region 
faces a personnel shortage to meet the growing demands generated by expansions of coverage; moreover, existing staff must be upgraded with the right competences and qualifications. The experience of Trinidad and Tobago is worth highlighting in the area of training for early childhood education teachers and may provide valuable lessons beyond the scope of the education sector.

Trinidad and Tobago has carried out important efforts to strengthen both its in-service training system as well as its pre-service training initiatives. In the area of in-service professional development, the country recently approved the Standards of Practice for the Teaching Profession in the Caribbean Community, which, importantly, includes an in-service professional development path for early childhood education teachers that is expected to transform how professional development is perceived, implemented, and actualized. Aligned with these standards, the country recently approved a new in-service Professional Development Model, which is composed of four career stages, with distinct teacher expectations described at each stage. In order to progress from one career stage to the next, teachers must acquire knowledgein-practice and demonstrate their ability to meet the relevant performance standards. Modern views of professional development characterize professional learning as a long-term process that extends from university to in-service training in the workplace. Additionally, the model values informal training (e.g., workplace interactions) that facilitate learning and that inspire teachers to alter or reinforce their teaching and educational practices.

With the goal of improving the pre-service training model for early childhood education teachers, in 2012, the Trinidad and Tobago Ministry of Education, in collaboration with the main teacher-training institutes in the country, worked to align the pre-service training curriculum for teachers who educate children between 3 and 5 years of age across eight universities. These eight institutions now offer the program, which will become a mandatory requirement for teachers interested in a permanent position as early childhood educators.

Although Trinidad and Tobago has taken important steps to professionalize early childhood teachers, challenges are likely to arise as this model is implemented. One major hurdle is that, as of now, early childhood teachers are not recognized as regular teachers under the law, and hence they are not eligible to receive the same benefits as other teachers (including participating actively in teachers' unions, for example). 


\section{Putting the Pieces Together: Policy Recommendations}

The emphasis on development in early childhood is growing in many countries in Latin America and the Caribbean. New laws and policies, framework documents, and regulatory or guidance materials have been produced. Political leaders have expressed commitment to the sector, generating public will and enthusiasm. National, subnational, and local governments are implementing innovative programs, often significantly increasing the number of direct services available to children and families. The philanthropic and business communities are partnering with governments to enhance services. And yet, enormous challenges remain to ensure that quality services reach those children who need them the most. Four main recommendations emerge from this chapter.

First, a focus on programs is necessary, but not sufficient: The region requires a systemic orientation that values both programs and the institutional architecture that supports them. High-quality, equitably distributed, and sustainable services cannot be achieved merely from a programmatic perspective.

This book does not advocate any one form of governance structure. It does, however, advocate putting in place the functions typically carried out by a consolidated structure: notably, comprehensive planning, establishing quality standards, monitoring functions, developing appropriate data systems, coordinating services across sectors and levels of government, and developing public information regarding child development.

One possible and promising approach to achieve coordination is using BSEs. To coordinate efforts successfully, BSEs must meet a set of institutional, fiscal, and political conditions. Institutionally successful BSEs have three key characteristics: authority over programs and policies-rather than simply deliberative or convening roles; built-in horizontal and vertical cooperation mechanisms; and a strong monitoring and evaluation component. Fiscally successful BSEs need a sufficiently large and stable budget to allow for long-term planning; they also need budget authority to allocate funds flexibly according to strategic needs. Politically, BSEs must enjoy enough support to induce cooperation across the sectors they seek to coordinate; 
conversely, BSEs must be perceived as politically neutral-rather than associated with a specific sector or administration-to ensure longevity. In countries where there is no BSE, other efforts, notably through data and accountability mechanisms, can serve as coordination vehicles.

Second, the system should reduce disparities, not enhance them: Services for the poor do not have to be poor services. However, often the allocation of funding, technical capacity, human resources, and program standards contribute to reinforce disparities rather than reduce them.

This problem is more obvious in decentralized systems but is not exclusive to them. Disparities cannot be solved with a single policy instrument. For example, it is not enough to provide more funding in less affluent localities if there are no incentives at the local level for the money to be spent efficiently. Thus, compensatory funding is necessary but it should be accompanied by other policies that foster the provision of quality services.

Third, accountability mechanisms need to be in place: Policies and programs for young children in the region lack a robust system of accountability. To date, quality monitoring mechanisms have largely focused on outputs (rather than on child outcomes or impacts). A key policy action is to produce reliable and centralized information on child development outcomes that can be shared among providers. This is needed to ensure that every child receives the attention that she requires. Urgent steps must be taken to decide what child development measure should be collected and to start following (at the least) the most disadvantaged children. Understanding their development path will provide valuable cues for deciding how public policy can best serve them.

Fourth, human resource investments should precede expansions of coverage: Quality outcomes are contingent upon quality personnel, but countries in the region still face serious challenges to attract and keep qualified personnel to deliver services to young children.

In many cases, this is driven by a fragmented view of the labor market that does not recognize that providers of early childhood services are competing for quality personnel with many other areas of the public sector and the economy. 
Countries must develop a systematic and competitive approach to recruit, train, retain, and motivate workers that provide services to children. Investments in human resources are the foundation on which any expansion in coverage and improvement in services need to be built.

The potential returns to public investment in early childhood are being compromised by the absence of a systemic understanding of the policy challenges in providing quality services to young children. As important as picking the right programs is the development of an institutional architecture to support them.

(c) (i) $\Theta$ Except where otherwise noted, this work is licensed under a BY NC ND Creative Commons Attribution-NonCommercial-NoDerivatives 3.0 IGO License. To view a copy of this license, visit https://creativecommons. org/licenses/by-nc-nd/3.0/igo/ 